\title{
Heat-related mortality amplified during the COVID-19 pandemic
}

\author{
Pedro M. Sousa ${ }^{1,2} \cdot$ Ricardo M. Trigo $^{2,3} \cdot$ Ana Russo $^{2} \cdot$ João L. Geirinhas ${ }^{2} \cdot$ Ana Rodrigues $^{4} \cdot$ Susana Silva $^{4} \cdot$ Ana Torres $^{4}$
}

Received: 11 March 2021 / Revised: 2 August 2021 / Accepted: 7 September 2021 / Published online: 21 January 2022

(c) ISB 2022

\begin{abstract}
Excess mortality not directly related to the virus has been shown to have increased during the COVID-19 pandemic. However, changes in heat-related mortality during the pandemic have not been addressed in detail. Here, we performed an observational study crossing daily mortality data collected in Portugal (SICO/DGS) with high-resolution temperature series (ERA5/ ECMWF), characterizing their relation in the pre-pandemic, and how it aggravated during 2020. The combined result of COVID-19 and extreme temperatures caused the largest annual mortality burden in recent decades $(\sim 12000$ excess deaths [ 11\% above baseline]). COVID-19 caused the largest fraction of excess mortality during March to May (62\%) and from October onwards (85\%). During summer, its direct impact was residual, and deaths not reported as COVID-19 dominated excess mortality (553 versus 3968 ). A prolonged hot spell led mortality to the upper tertile, reaching its peak in mid-July $\left(+45 \%\right.$ deaths/day). The lethality ratio $\left(+14\right.$ deaths per cumulated $\left.{ }^{\circ} \mathrm{C}\right)$ was higher than that observed in recent heatwaves. We used a statistical model to estimate expected deaths due to cold/heat, indicating an amplification of at least $50 \%$ in heatrelated deaths during 2020 compared to pre-pandemic years. Our findings suggest mortality during 2020 has been indirectly amplified by the COVID-19 pandemic, due to the disruption of healthcare systems and fear of population in attending healthcare facilities (expressed in emergency room admissions decreases). While lockdown measures and healthcare systems reorganization prevented deaths directly related to the virus, a significant burden due to other causes represents a strong secondary impact. This was particularly relevant during summer hot spells, when the lethality ratio reached magnitudes not experienced since the 2003 heatwaves. This severe amplification of heat-related mortality during 2020 stresses the need to resume normal healthcare services and public health awareness.
\end{abstract}

Keywords Heatwaves · Mortality $\cdot$ Public Health $\cdot$ COVID-19

\section{Introduction}

Heatwaves (HWs) are one of the major causes of excess mortality (Forzieri et al. 2017; WHO 2018). In fact, acute heat stress is already recognized as a growing cause of death in the developed world (USAID 2019). Out-of-hospital

Pedro M. Sousa

pedro.sousa@ipma.pt

1 Instituto Português Do Mar E da Atmosfera (IPMA), 1749-077 Lisboa, Portugal

2 Instituto Dom Luiz (IDL), Faculdade de Ciências, Universidade de Lisboa, 1749-016 Lisboa, Portugal

3 Departamento de Meteorologia, Instituto de Geociências, Universidade Federal do Rio de Janeiro, Rio de Janeiro 21941-916, Brazil

4 Instituto Nacional de Saúde Doutor Ricardo Jorge (INSA), Avenida Padre Cruz, 1649-016 Lisboa, Portugal cardiac arrest (OHCA) rates have been shown to increase significantly during extreme heat episodes (Kang et al. 2016; Onozuka and Hagihara 2017). Also, other complications associated to kidney or respiratory diseases (Borg et al. 2017; Lee et al. 2018) increase during such episodes, resulting in a significant burden over fragile groups (Benmarhnia et al. 2015; Cheng et al. 2019; Kenny et al. 2010). Although there is consensus on the fact that HW increases the risk of mortality by cardio/respiratory causes, the effects of HW on morbidity outcomes are geographically distinct due to a variety of socio-economic factors (Péres et al. 2020; Phung et al. 2017; Sherbakov et al. 2018), ranging from infrastructures quality, access to air conditioning, public/social awareness to very different resiliences of health systems. As a consequence, these discrepancies may prompt a delayed and sometimes ineffective action by policy makers and responsible authorities. 
The historical European $2003 \mathrm{HW}$ has been considered as a "wake up call," when the link between the tragic mortality toll (> 70000$)$ and the record-breaking heat episode has been extensively studied (Fouillet et al. 2007; Mitchell et al. 2016; Robine et al. 2008). The initial stages of the $2003 \mathrm{HW}$ struck Portugal in early August (Calado et al. 2004), causing more than 2000 excess deaths during that period (Trigo et al. 2009). As a result, awareness, preparedness, and mitigation procedures were improved and implemented widespread after that event (Fouillet et al. 2007; García-Herrera et al. 2010; Nunes et al. 2011). Nevertheless, despite the increased protection of risk groups in the post-2003 event, extreme temperature events (both cold and warm) continue to trigger some of the most significant mortality peaks in Portugal, as the ones observed during July 2013 (Silva et al. 2016) or August 2018 (Torres et al. 2020), underlying that this issue remains critical in the post-2003 period.

Mortality records for 2020 reveal that we faced the deadliest July in Portugal since 1949 (10 430), even surpassing the death toll observed during August 2003, with more than 2000 deaths above the average for the time of the year (INE 2021; SICO-eVM 2021), even after excluding deaths reported as COVID-19 (SARS-CoV-2) related. In fact, any analyses on mortality rates since 2020 should take in account the atypical framing of the pandemic, which started to affect Portugal in mid-March, leading to the deadliest year on record. In this sense, while deaths related to the COVID-19 virus have undoubtedly contributed to the highest ever number of deaths in Portugal (at least since 2009), the incidence of COVID-19 as the direct main contributor to anomalous mortality has been essentially restricted to non-summer months (Nogueira et al. 2020a; Torres et al. 2021). During that season, other causes have dominated the persistent observed excess death rates. Within the wide range of other causes (including anomalous warm periods), a large fraction of excess mortality can be considered as a secondary effect of the COVID-19 pandemic, in particular due to reduced healthcare (Nogueira et al. 2020b). Likewise, studies in several countries have reported the common outcome during the pandemic of a significant increase in OHCA deaths (Marijon et al. 2020) in parallel with a decrease in emergency admission rates (Mafham et al. 2020; Mesnier et al. 2020) and OHCA survival rates (Uy-Evanado et al. 2021). A similar effect in healthcare admissions has been observed in Portugal since March (SNS 2021).

Here, we examine the anomalous mortality series during 2020 , in particular those cases related to the long warm spell that resulted in the warmest July ever observed in mainland Portugal since 1931 (IPMA 2020). In this regard, we provide a comparison between the magnitudes of excess heat-related deaths during 2020 with those observed in pre-pandemic years, in order to explore how the COVID-19 pandemic may have impacted heat-related mortality. Additionally, and relying on statistical modeling of expected mortality due to observed temperatures, as well on significant changes observed in hospital admissions during 2020, we discuss how the disruptions in the normal functioning of healthcare systems (in particular the reduction in ER admissions) may also have contributed to the observed burden.

\section{Methods}

\section{Mortality/health data}

Mortality data for Portugal (country totals, by district and by age group) were retrieved from the death certificate information system provided in the Direcção Geral da Saúde platform (SICO-eVM 2021, available at https://evm.min-saude. $\mathrm{pt} /$ ). The total national values are available for the period spanning 2009-2020, except for regional and age group data (used in Supplementary Material Figs. S1-S2), only available since 2014. Baseline intra-annual mortality values were computed using the 2009-2019 reference period, removing periods characterized by the influenza epidemic and/or events with potential impact on mortality (such as extreme temperatures), and adjusting it for each year based on the observed trend in total deaths during the study period ( +870 deaths/year, $p=0.05$ ). Figure 1 depicts the evolution of annual and 3-month seasonal total deaths. Cumulative and anomaly mortality series were computed for each calendar day, in respect to the yearly adjusted baselines.

Daily deaths reported as COVID-19 were obtained from the daily reports provided by DGS (available at https:// covid19.min-saude.pt/). Deaths not directly attributable to COVID-19 correspond to the number of total daily deaths minus those reported as COVID-19.

Daily data for emergency room (ER) attendance from the Portuguese National Health System (Sistema Nacional de Saúde, SNS, 2021) was retrieved, including Manchester triage system classification. Admissions during 2020 were compared against those registered since 2017 , in order to estimate the percentage of decrease in ER admissions throughout the pandemic. Note that these values only refer to public health services (excluding private healthcare ER changes) and thus corresponding to $57 \%$ of the national ER admissions through the considered period.

\section{Meteorological data}

Daily maximum (Tmax), minimum (Tmin), and mean (Tmean) temperature values were extracted from the ERA5 reanalysis dataset (the fifth-generation atmospheric reanalysis from the European Centre for Medium-Range Weather Forecasts, Hersbach et al. 2020), in a $0.25^{\circ} \times 0.25^{\circ}$ horizontal resolution grid, considering averaged values over continental 


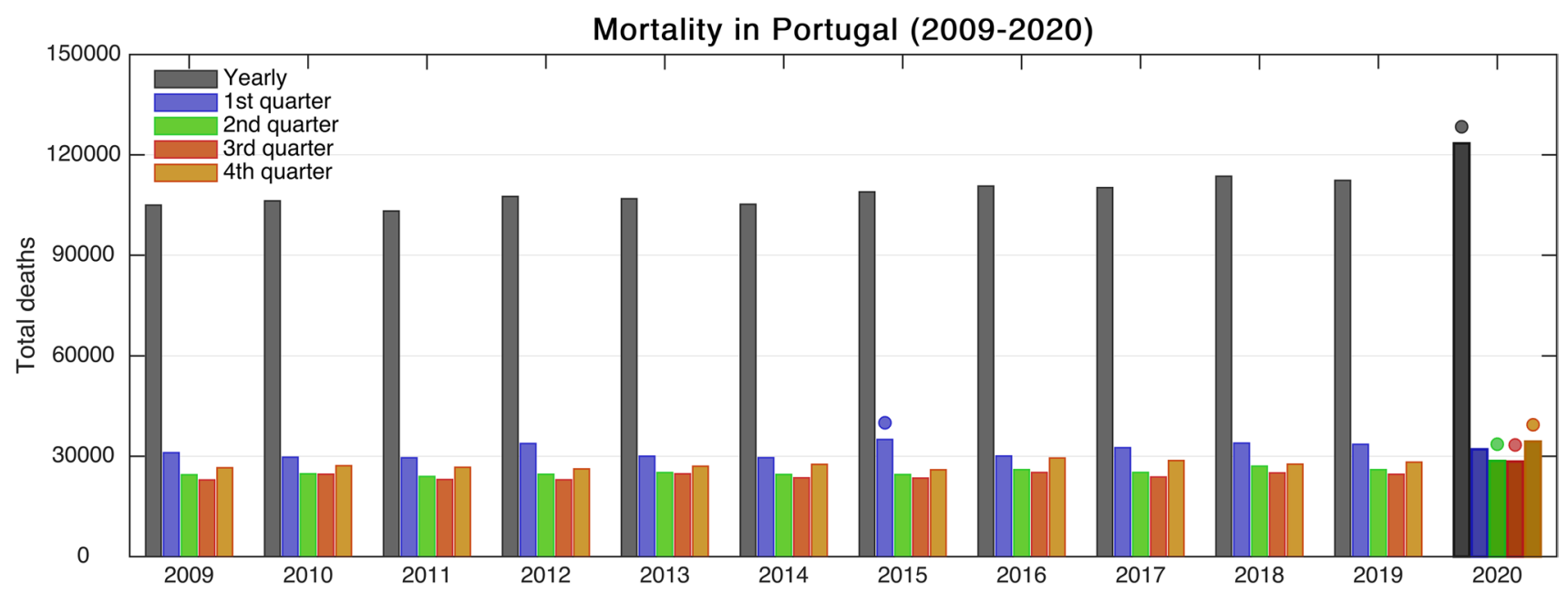

Fig. 1 Evolution of annual total mortality in Portugal since 2009 (gray bars) and separated by 3-month quarters (colored bars). Filled circles highlight the highest value throughout 2009-2020 (Color figure online)

Portugal, except for the regional analysis presented further ahead. Climatological reference values were computed for the 1990-2019 reference period, and all anomalies were calculated in respect to that period. The ERA5 reanalysis has been shown to provide very good matching with station observational data, in particular during extreme temperature episodes (Sheridan et al. 2020).

Countrywide HW periods were considered as those where spatially averaged Tmax was above the 90th percentile of the calendar day climatology for at least 5 days. For each HW, we analyzed deviations in mortality, crossing these with temperature anomalies. The ratio between excessive mortality and cumulated temperature anomalies (above the minimum mortality temperature, MMT, as detailed below) was defined as the lethality ratio of each HW.

Daily averages (Tmean) were used for the expected mortality statistical model (see details below), being these spatially weighted according to the population density distribution over continental Portugal. The same approach was tested using also Tmin and Tmax, with no significant gains in model performance, in agreement with previous results by Gasparrini et al. (2015).

\section{Heat-/cold-related mortality statistical model}

Overall HW impacts on mortality or morbidity are normally derived from time series regression models that treat heatwave occurrence as a binary variable and do not control for temperature (Cheng et al. 2019; Gasparrini and Armstrong 2011). This caveat is partially overcome when the evidence for the attributable risk of temperature is accounted (Gasparrini et al. 2015; Guo et al. 2018). Nevertheless, this approach is often restricted to extreme events and not accounting to the continuity of temperature values (Gasparrini et al. 2015). One way to overcome this limitation is to rely on statistical modeling approaches which allow to account for the complex temperature-mortality dependency, calculating the total mortality burden attributable to non-optimum ambient temperatures. The relation between excessive cold/heat varied in locations, showing the existence of an "optimal" temperature for minimized mortality (hereafter MMT) (Gasparrini et al. 2015) and significant increases towards both extreme cold and heat conditions.

Therefore, a statistical model for the expected daily deaths from heat/cold was developed and calibrated by adjusting a polynomial fit to the daily mortality data versus Tmean averaged during the previous days and considering the period spanning 2009-2019. Following the methodologies applied by several authors (Gasparrini et al. 2015; Lian et al. 2020; Péres et al. 2020), we performed sensitivity tests for the individual lag times which maximize observed daily deaths due to cold and heat conditions. Thus, separate regressions were applied for opposite ranges of temperature extremes, resulting on time windows of 14 days and 4 days, for cold and hot conditions, respectively. Sensitivity tests using different time windows (ranging between 2 and 21 days) were performed in order to minimize the spread in scatterplots, as well as to maximize (minimize) correlations coefficients (errors) in the model performance during the calibration, as illustrated in Figs. S3 and S4.

The "optimal" temperature for minimized mortality (MMT) was defined as $20^{\circ} \mathrm{C}$, and thus separate analysis was performed for cold/warm conditions, taking into account the different time windows. However, as a result of optimized thresholds 
(for both minimal mortality and lag times), a good match is found in the scatterplot data at the cold/heat interface, thus enabling the use of a single regression curve, which is defined by the following equation:

$$
\begin{aligned}
\text { Daily Deaths }(d)= & 0.0244 \times \overline{\text { Tmean }_{(d-N: d)}} \text { - } \\
& -1.6869 \times{\overline{\text { Tmean }_{(d-N: d)}}}^{2} \\
& +43.8769 \times{\overline{\text { Tmean }_{(d-N: d)}}}^{2}+2520
\end{aligned}
$$

In the previous equation, the overbar denotes the average daily temperature since $N$ days before the target day $d$, with $N=13$ for cold conditions and $N=3$ for warm conditions. The superscripts correspond to the polynomial degree of each equation term. Like for observational mortality values, these modeled values were also adjusted taking into account the observed trend in absolute mortality during 2009-2019 (+870 deaths/year, $p=0.05$ ).

The modeled values obtained from the regression were then considered as the expected mortality due to meteorological conditions. Moreover, the performance of the model was further enhanced with some additional corrections, as listed below:

i) Raw modeled values were adjusted to the 2009-2019 observed trend in mortality in Portugal.

ii) A correction factor to accommodate increased mortality due to abrupt changes from mild to hot conditions was included (Geirinhas et al. 2020).

iii) A relieving factor based on the previous 60-day mortality was also considered, in order to accommodate the decrease in still existing fragile individuals after severe mortality peaks.

A coefficient to introduce a correction due to increased mortality during episodes characterized by sudden warming (ii) was idealized. Relevant mortality increases are frequently observed when temperatures increase quickly from mild to warm conditions (even without very extreme absolute values). This initial impact is not accommodated by an overall simple temperature-mortality model and has previously been addressed in works such as Nairn et al. (2009) or Geirinhas et al. (2020), by using indices such as the excess heat factor $(E H F)$. Here, we propose a modified version of the previous, in order to estimate an initial aggravating factor for sudden temperature rises before an eventual "acclimatization" to warm conditions during prolonged hot spells, thus defining it as an extreme heat adaptation index (EHA) and consisting in the following formulation:
$E H A=\left(1-E H_{\text {addapt }}\right) \times E H_{\text {racio }} \times E H_{\text {change }}$

This index has ${ }^{\circ} \mathrm{C}$ units, with $E H A=0$, meaning no significant impact, and higher values reflecting an aggravation factor in Tmean occurring when individuals do not have sufficient time to habituate to warm conditions. EHA values are thus summed to the observed Tmean, functioning as an "effective" temperature during heat events abrupt onsets. Each sub-index used to compute $E H A$ is defined as follows:

$E H_{\text {addapt }}=\left[\text { fraction of days with Tmean }>20^{\circ} \mathrm{C}\right]_{d-14: d}$

$$
\begin{aligned}
E H_{\text {racio }} & =\frac{\overline{\text { Tmean }_{(d-3: d)}}-\text { Tmean }_{P C T 10}}{\text { Tmean }_{P C T 90}-\operatorname{Tmean~}_{P C T 10}} \\
E_{\text {change }} & =\overline{\text { Tmean }_{(d-3: d)}}-\overline{\operatorname{Tmean}_{(d-18: d-4)}}
\end{aligned}
$$

The overbar denotes once again average values during specific time windows, and PCT10 and PCT9O refer to the 10th and 90th percentiles of Tmean during all days within the climatological reference period (1990-2019). $E H_{\text {addapt }}$ and $E H_{\text {racio }}$ are dimensionless and forced to remain $\geq 0$, with the former defining the degree of accommodation to high temperatures and the latter defining the heat intensity during the target time window, when compared to the climatology. $E H_{\text {change }}$ estimates the absolute magnitude of the sudden temperature change, in ${ }^{\circ} \mathrm{C}$.

Finally, the previous 60-day average relative excess in mortality was calculated for each day, and that fraction was subtracted to the previously modeled excess deaths for that day. This was performed in order to accommodate the decrease in available fragile individuals after severe mortality peaks (iii), which would lead to overestimated predicted mortality values (e.g., long-lasting or consecutive HWs) without such an adjustment. These "fine tuning" procedures enabled the model performance during the calibration period to be enhanced by $\sim 5-10 \%$. The validation of its performance during 2009-2019 is presented in Fig. S4. This model was then applied to 2020 meteorological datasets to estimate expected heat-/cold-related deaths (without considering the health system and structural/societal changes associated with the COVID-19 pandemic).

\section{Results}

\section{Evolution of mortality series in Portugal during 2020}

The analysis of total daily mortality in Portugal during 2020 reveals the largest number of total deaths in recent decades $(123,753)$ (see Fig. 1), as a result of several periods with 
a)

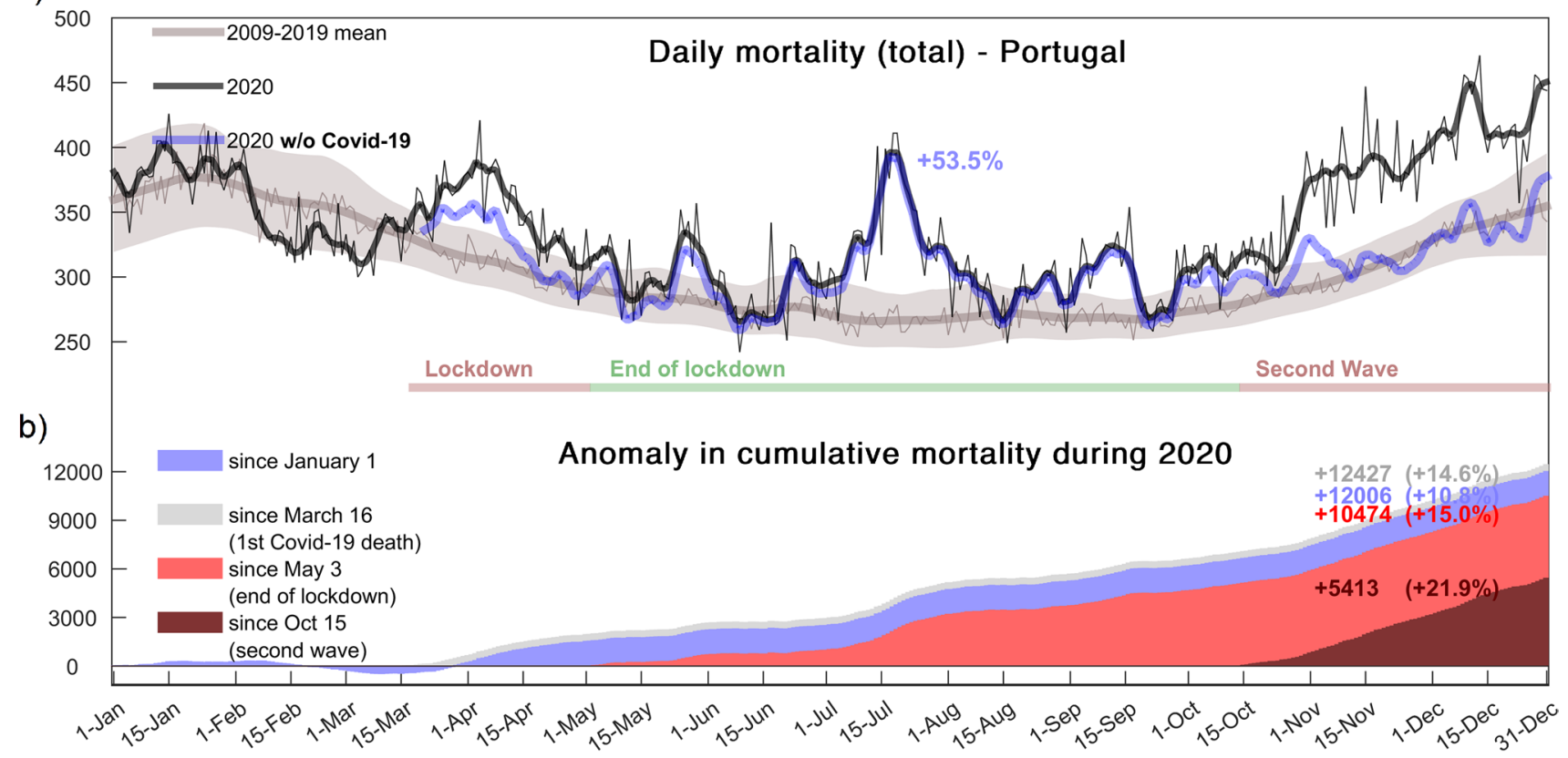

Fig. 2 a Daily mortality in Portugal during 2020 (total deaths in black and excluding COVID-19 deaths in blue) against the baseline for each calendar day (2009-2019 in gray). Thin lines represent daily absolute values and thick lines after applying a 7-day smoothing. Envelope shows the $1 \sigma$ interval for the baseline. b Shaded areas represent cumulative mortality anomalies in Portugal during 2020 w.r.t. to 2009-2019 and since January 1 (gray), March 16 (first official COVID-19 death, blue), May 3 (end of lockdown measures, light red), and during the second COVID-19 wave (dark red). Note that all mortality values were adjusted to the observed trend during 2009-2019

while the nation was under a strict lockdown. As a result, between March and May, 1424 COVID-19 deaths (62\% of the excess) were registered.

Lockdown measures gradually became less strict throughout May, as mortality rates attributed to COVID-19 progressively diminished. However, the contribution of COVID-19 deaths to excess rates only became residual by June. Accordingly, a relatively small, but non-negligible direct contribution of COVID-19 should still be attributed to the mortality peak observed during late May. However, the meteorological contribution is undeniable, as during this period, temperatures in continental Portugal evolved to heatwave conditions, quickly followed by a similar response in the daily number of deaths, as shown by the good agreement between anomalous mortality and temperature anomalies observed in the series presented in Fig. 3a.

This period was followed by a relatively cool month of June, with near-average (or slightly above) mortality rates, until the onset of the prolonged hot spell later in that month. This persistent heat episode lasted throughout early August, including the warmest July since 1931 (IPMA 2020). This prolonged heatwave presented its peak by midJuly (Fig. 3a), where spatially averaged temperatures in Portugal were $\sim 4{ }^{\circ} \mathrm{C}$ above the expected climatological values, and simultaneously daily mortality rates peaked again directly related to COVID-19 were consistently above 30 , 


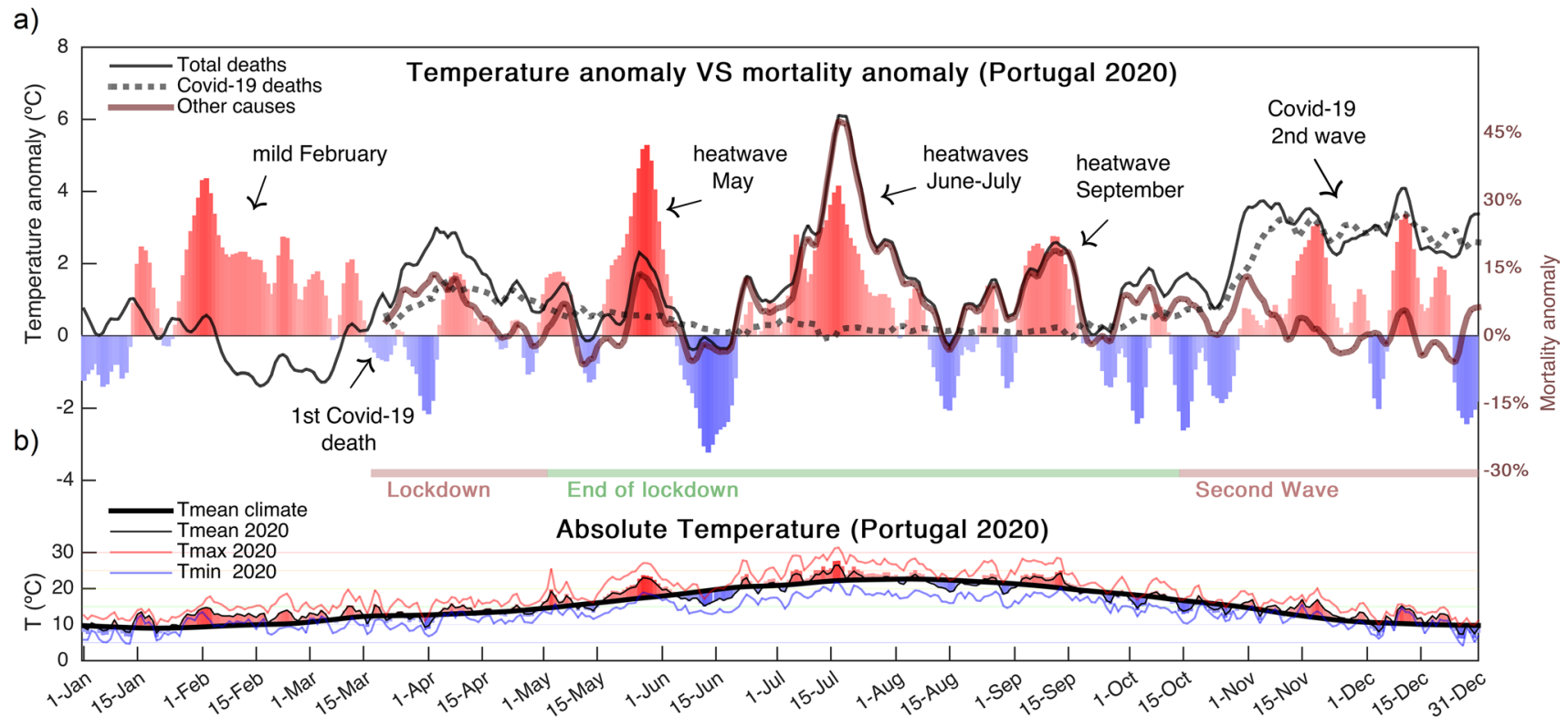

Fig. 3 a Mortality versus spatially averaged temperature anomalies. Red and blue bars represent positive and negative temperature anomalies, respectively. Lines depict the relative anomaly in mortality, considering all deaths (solid black line), COVID-19 deaths (dashed black line), and all causes except COVID-19 (brown line). A 7-day

above 400 (which represents an excess anomaly of approximately $+45 \%$, with only $\sim 2 \%$ of those directly reported as COVID-19). Another hot period with significant excessive mortality was observed during the first half of September. This reinforces the critical role of the HW mechanism during this period, in contrast with the minor role played by deaths reports as COVID-19. We have also analyzed this relation for sub-regions of Portugal (see Supporting Material Fig. S2), showing that (i) the same temperature-mortality link is evident at regional scales and (ii) it was more persistent in inland areas, whereas conditions returned to values closer to normal in the highest populated coastal districts of Lisbon and Porto after the HW peak. As by mid-August temperatures returned to values closer to normal (or slightly below average), mortality exceedance rates dropped to values below $10 \%$. However, during most of the period since mid-June, deaths from all causes not reported as COVID-19 were consistently above average (particularly notable in the highly populated area of Lisbon), even during periods with relatively modest positive temperature anomalies, thus suggesting an amplification of mortality during 2020, as it will be discussed in the following sub-section.

As stated before, after the end of the warm season (Fig. 3b), from October onwards, mortality anomalies were again mainly driven by the consistent increase in COVID19 incidence. At the end of the year, a total excess of 5400 deaths above average was observed between October 15 and December 31 , corresponding to $a+21.9 \%$ relative smoothing has been applied to these anomaly series. b Absolute values for the daily mean temperatures (thin black line and colored shaded areas), maximum temperatures (thin red line), and minimum temperatures (thin blue line) in continental Portugal during 2020 are shown in the lower panel

cumulative anomaly (Fig. 2b). From those, 4995 deaths ( $85 \%$ of the excess during this period) were registered as COVID-19.

\section{Amplification of heat-related deaths during the pandemic}

As abovementioned, excess mortality in Portugal between May and September was controlled to a large extent by extreme hot weather events. The first (late May) and last one (early September) were relatively short in duration, although significant from a mortality perspective. On the other hand, the mid-event was much longer (from late June to early August), despite some very brief relief periods, and presenting a prominent peak by mid-July. Although these events were characterized by significant temperature anomalies at countrywide scale, those were not as high as in relevant heat-mortality events of previous years. In Table 1, we show a comparison between the periods during 2020 with well-known previous heatwave events in recent years in Portugal, including the historical 2003 HWs, all characterized by excess mortality.

Results presented in Table 1 show evidence of significantly enhanced heat-related mortality during the four HW episodes of 2020. During the HW event in May, and despite significant relative anomalies ( $\operatorname{Tmax}$ anomaly of $+5.5^{\circ} \mathrm{C}$ ) and the rapid onset of HW conditions, averaged temperatures were not particularly outstanding $\left(\right.$ Tmean $\left.=22.2{ }^{\circ} \mathrm{C}\right)$. 
Table 1 Excessive mortality during the different HW events in 2020 compared with previous notorious HW events in Portugal

\begin{tabular}{|c|c|c|c|c|c|c|c|c|}
\hline Event & $\begin{array}{l}\text { 12-20 Jun } \\
1981(\#)\end{array}$ & $\begin{array}{l}\text { 30Jul to } 15 \mathrm{Aug} \\
2003(*)\end{array}$ & $\begin{array}{l}5-12 \text { Jul } \\
2013\end{array}$ & $\begin{array}{l}16-20 \text { Jun } \\
2017\end{array}$ & $\begin{array}{l}1-5 \text { Aug } \\
2018\end{array}$ & $\begin{array}{l}20-25 \text { May } \\
2020\end{array}$ & $\begin{array}{l}17-21 \mathrm{Jul} \\
2020\end{array}$ & $\begin{array}{l}\text { 11-14 Sep } \\
2020\end{array}$ \\
\hline $\begin{array}{l}\text { Duration } \\
\text { (days) }\end{array}$ & 9 (\#) & $17(*)$ & 8 & 5 & 5 & 6 & 5 & 5 \\
\hline $\begin{array}{l}\text { Tmax } \\
\text { Anomaly }\left({ }^{\circ} \mathrm{C}\right)\end{array}$ & $+6.5^{\circ} \mathrm{C}$ & $+4.7^{\circ} \mathrm{C}$ & $+6.1^{\circ} \mathrm{C}$ & $+7.6^{\circ} \mathrm{C}$ & $+6.6^{\circ} \mathrm{C}$ & $+5.5^{\circ} \mathrm{C}$ & $+4.0^{\circ} \mathrm{C}$ & $+4.6^{\circ} \mathrm{C}$ \\
\hline $\begin{array}{l}\text { Tmean } \\
\left({ }^{\circ} \mathrm{C}\right)\end{array}$ & $25.1^{\circ} \mathrm{C}$ & $26.8^{\circ} \mathrm{C}$ & $26.3^{\circ} \mathrm{C}$ & $26.6^{\circ} \mathrm{C}$ & $27.7^{\circ} \mathrm{C}$ & $22.2^{\circ} \mathrm{C}$ & $25.7^{\circ} \mathrm{C}$ & $23.7^{\circ} \mathrm{C}$ \\
\hline $\begin{array}{l}\text { Cumulated } \\
{ }^{\circ} \mathrm{C}>\mathrm{MMT}\end{array}$ & $+46.0^{\circ} \mathrm{C}$ & $+114.8^{\circ} \mathrm{C}$ & $+50.8^{\circ} \mathrm{C}$ & $+33.3^{\circ} \mathrm{C}$ & $+38.6^{\circ} \mathrm{C}$ & $+13.3^{\circ} \mathrm{C}$ & $+28.3^{\circ} \mathrm{C}$ & $+14.8^{\circ} \mathrm{C}$ \\
\hline Excess deaths & 1906 (\#) & 2399 (*) & +908 & +208 & +350 & $+312(+232)$ & $+586(+526)$ & $+216(+196)$ \\
\hline $\begin{array}{l}\text { Mean excess } \\
\text { rate }(\%)\end{array}$ & -- & -- & $+43 \%$ & $+15 \%$ & $+26 \%$ & $+18 \%(+14 \%)$ & $+43 \%(+42 \%)$ & $+20 \%(+18 \%)$ \\
\hline $\begin{array}{l}\text { Lethality ratio } \\
\left(\text { deaths } /{ }^{\circ} \mathrm{C}\right)\end{array}$ & +41 & +21 & +18 & +6 & +9 & +17 & +19 & +13 \\
\hline
\end{tabular}

The numbers in brackets for the 2020 events represent deaths from all causes not reported as COVID-19. Note that excess deaths were adjusted to the observed trend in total mortality during 2009-2019. A minimum mortality temperature (MMT) of $20{ }^{\circ} \mathrm{C}$ was considered for Portugal. Mortality data for the 2003 HW (*) adapted from Trigo et al. (2009) and for the 1981 HW (\#) adapted from Garcia et al. (1999) are both shown for comparison purposes only

However, these heat stress conditions still led to significant increased mortality, probably due to the early character of this HW (García-Herrera et al. 2005). Regarding the July $\mathrm{HW}$, Tmax anomalies $\left(+4.0^{\circ} \mathrm{C}\right)$ were also lower than those observed in previous HWs (e.g., $+6.6^{\circ} \mathrm{C}$ in the early August $2018 \mathrm{HW} ;+6.1{ }^{\circ} \mathrm{C}$ during the July $2013 \mathrm{HW} ;+7.6^{\circ} \mathrm{C}$ during the June $2017 \mathrm{HW}$ ). On one hand, despite the outstanding persistence of the 2020 warm spell (warmest July ever in Portugal) (IPMA 2020), the absence of any record-breaking absolute values explains a modest monthly anomaly $(+2.6$ $\left.{ }^{\circ} \mathrm{C}\right)$. On the other hand, and despite the persistency of the warm spell, observed absolute temperatures fall short of those of previous events, thus suggesting the amplification of heat-related mortality during 2020 . To address this in further detail, we also analyzed other metrics. For example, the cumulated Tmean anomaly (above MMT) during the peak of the 2020 hot spell (17-21 July) was lower than those observed during recent episodes with the same duration (2017 and 2018). However, the lethality ratio during the July 2020 HW was higher than what was attained in those previous episodes similar in duration, being only surpassed by past events with significantly longer durations. In fact, this increase in the lethality burden was present throughout most of July 2020 (despite brief mild periods in between), as it was also notable during the short (and relatively mild) HWs observed in May and September. This reinforces the fact that, even moderately warm periods in 2020, HWs were more lethal than expected. To deepen the issue of heatrelated amplification deaths in 2020, we explored the statistical model to estimate daily deaths expected due to cold/heat conditions in a non-pandemic scenario, comparing against the mortality observed in 2020 and crossing these results with ER admissions, as presented in Fig. 4.

In Fig. 4a, we compare the distribution of daily mortality according to temperature ranges during 2009-2019 versus 2020. It is clear that the 2020 distribution (even after removing COVID-19 deaths) has been shifted to a higher lethality ratio. Based on this relation, we calibrated the ratio of expected mortality for each temperature interval using the 2009-2019 pre-pandemic period (see Methods and Supporting Material for specific model details and verification). This empiric model performs very well during the calibration period (correlation coefficients $>0.80$ and average daily error 7\%) (see Fig. S4), in particular for hot spells (e.g., July 2013; June 2017; August 2018). Deaths related to cold spells tend to present a more diffuse and prolonged behavior in time (Analitis et al. 2008; Antunes et al. 2017), particularly during seasonal influenza outbreaks. For example, a prolonged period with above-average mortality during the winter season of 2016-2017 was not fully captured by the model, as a result of a particularly severe influenza strain circulating in Europe during that period (ECDC 2019).

The model was then applied to meteorological conditions observed during 2020, as shown in Fig. 4c-d. The fit is able to capture well the periods where above-/below-average mortality from non-COVID-19 causes was observed. However, in general, it does not depict the magnitude of the mortality peaks during hot spells observed in 2020, unlike in previous years (see Supplementary Figure Fig. S4), thus pointing to an amplification due to other confounding factors. In this context, we would like to stress the extent of the ER admissions dropdown since early March in Portugal (Fig. 4b). While this decline in ER admission was stronger 

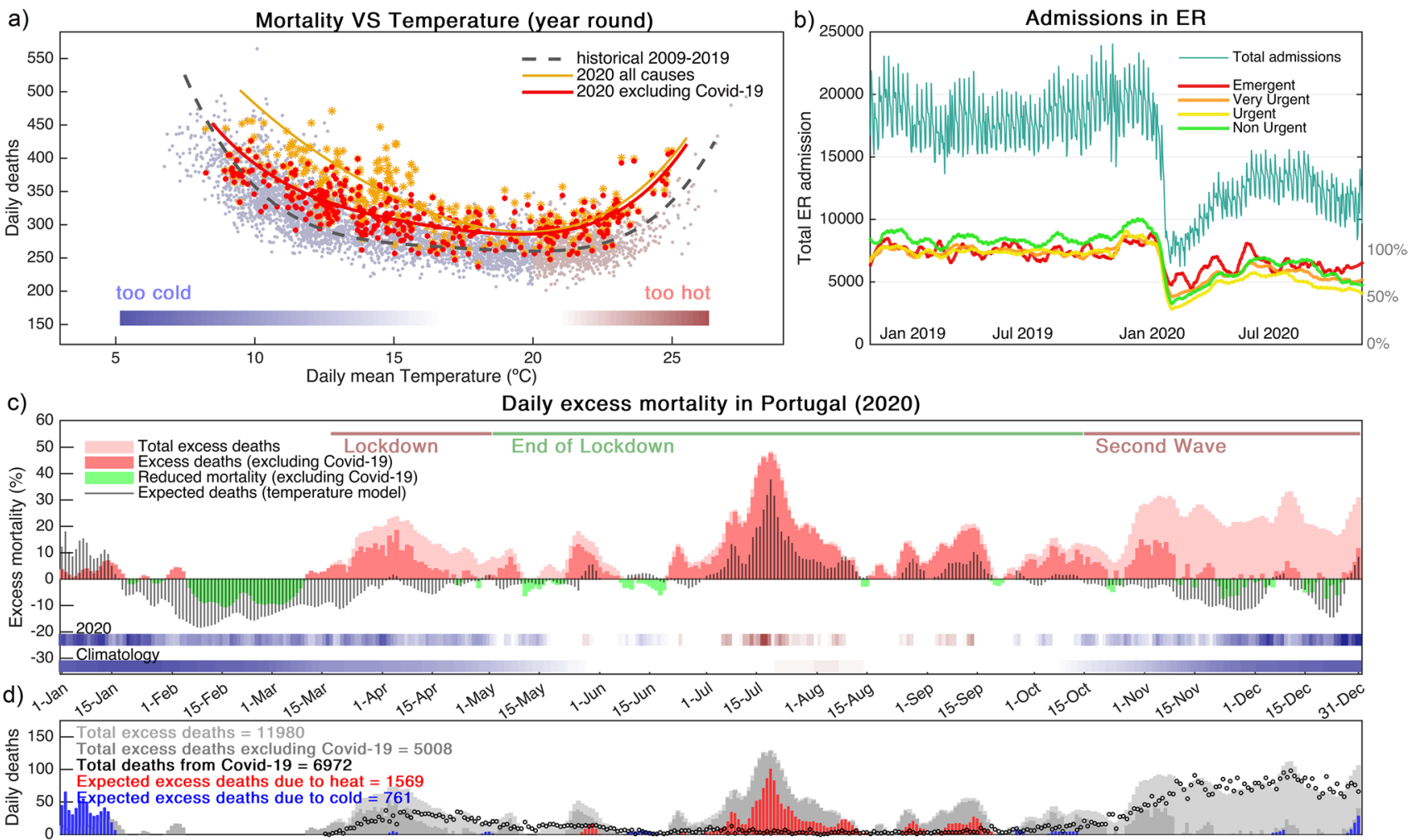

Fig. 4 a Scatter plot for daily mortality versus the previous days averaged mean daily temperature during 2009-2019. Light red dots correspond to the average temperatures between day 3 and concurrent day, when this value is $\geq 20{ }^{\circ} \mathrm{C}$, defining the heat-related mortality model. Light blue dots represent the remaining days, using average temperatures between day 13 and the concurrent day, defining the cold-related mortality model. Dashed adjusted curve is relative to 2009-2019. For 2020, the orange line represents the fit considering all deaths $(*)$, while the thick red line represents the fit when excluding COVID-19 deaths (). b Total number of reported emergency admissions in SNS between January 2019 and 31 December 2020

during the first pandemic wave (reaching values below 50\% of the average for 2019), it still remained significant throughout the rest of 2020 and extensive to different triage classes, albeit less evident (as expected) for the emergent class.

Finally, and focusing exclusively on deaths not registered as COVID-19 between May and September, we compared the average mortality rate anomalies outside hot days (Tmean $<$ MMT, with a maximum excess of $+25 \%$ and an average excess of $+5 \%$ ), with that observed during warm days (Tmean $>$ MMT, with a maximum excess of $+58 \%$ and an average excess of $+17 \%$ ). During these warm periods, the total number of excess deaths not registered as COVID-19 (4 053) was much higher than those expected by our statistical model (1569 total, Fig. 4d). This suggests an amplification of at least $50 \%$ in heat-related deaths during 2020 , although probably higher on average, taking into account that even after removing those 5\% (averaged outside hot days) from the observed mortality excess, the ratio to modeled deaths (cyan line), highlighting the decrease observed during the COVID19 pandemic for different triage levels (retrieved from https://www. sns.gov.pt/monitorizacao-do-sns/servicos-de-urgencia/caracterizacaourgencias/). c Observed excess mortality during 2020 (total in light red and excluding COVID-19 in dark red), against modeled excess deaths (gray bars) by using the fit presented in Fig. 2a, compared to the 2009-2019 historical baseline. Colored bars at the bottom represent the climatological and 2020 values for the mean daily temperatures, using the color scale presented in $\mathbf{a}$. $\mathbf{d}$ The same as in $\mathbf{c}$ but breaking down modeled deaths due to excessive cold (blue) and heat (red), respectively. Black dots represent daily COVID-19 deaths

is larger than 2:1. It is also critical to note that these 4053 excess deaths observed during warm days correspond to $\sim 80 \%$ of the total deaths not registered as COVID-19 during the entire year (5 008).

\section{Discussion}

An unprecedented prolonged heat spell took place between late June and early August 2020 in Portugal with a significant impact in observed mortality, resulting in the highest number of fatalities ever recorded in July and also significantly contributing to the highest annual total mortality, amidst a very uncharacteristic year due to the start of the COVID-19 pandemic. To further highlight the relevance of these numbers, we stress that this significant death toll burden was observed despite a particularly benign winter of 2019-2020 in terms of mortality. In fact, February 
presented below-average mortality in Portugal, mostly as a result of a very mild season. An earlier than average start of the 2019-2020 influenza season in Europe (ECDC 2019) and in Portugal (INS 2021), in particular, with dominant circulation of influenza B (associated with milder disease) (Tran et al. 2016) and a co-circulation of $A(H 1 N 1) p d m 09$ virus (associated with lower excess mortality) (Freitas and Donalisio 2018) might also have contributed to below-average mortality rates in late winter of 2019-2020. We also note that influenza activity has been at baseline level during winter 2020-2021, likely due to the impact of the various public health and social measures implemented to reduce transmission of SARS-CoV-2. Nevertheless, the magnitude of the fingerprint left by the warm summer of 2020 in excess mortality is significantly larger than that observed during previous years HWs. Despite the relevant role of heat persistency for mortality rates (Geirinhas et al. 2020; Rocklöv et al. 2014; Royé et al. 2020), as observed during most of July 2020, the fact that absolute temperatures seem to fall short of those reached in previous events suggests an amplification of heat-related mortality during the pandemic. This is further advocated by the very high lethality ratios observed during the short and not particularly extreme HWs registered in May and September. Such results suggest a reduction in the capacity to mitigate heat-related deaths during the COVID-19 pandemic. Previous authors had already warned on the need to protect fragile groups to HW exposure amidst a pandemic scenario (Martinez et al. 2020). Here, we argue that inadequate preparation to the unfortunately very hot summer of 2020 in Portugal led to a lethality ratio only registered as recently as in the 2003 HWs. Our results help to confirm previous studies (Silva et al. 2016), showing that this ratio had significantly improved in extreme heat events after 2003. However, the contingency related to the COVID19 pandemic appears to have made heat-related mitigation and awareness measures recede to values registered during that infamous 2003 episode.

A drastic decrease in total hospital admission and treatment rates (which reached $\sim 2 / 3$ in its worst period and is not yet stabilized in the previous range of variability) is in phase with the pandemic start and certainly reflects societal behavior, namely, distress and fear of searching healthcare due to the COVID-19 crisis, and is not exclusive of Portugal (e.g., Mesnier et al. 2020). By exploring ER admission triage data in further detail, this reduction is notable for all levels, including the most severe classes. In fact, admissions close to pre-pandemic rates were only registered during short critical periods for the emergent class, while a clear decrease in urgent and very urgent cases became the norm, reflecting a change in healthcare demand from the public. This fact, together with the reorganization of healthcare systems to handle the rapid surge of the pandemic (including deferred routine medical activity), helps to explain why mortality rates due to causes not directly attributable to COVID-19 have increased dramatically. In this context, we argue that a relevant fraction of the additional mortality observed since March in Portugal should be explained by an increase in diverse causes of deaths. This increase became particularly notable during three episodes with high temperatures in May, July, and September, when heat-related mortality seems to have been seriously amplified by non-meteorological secondary causes. As a result, excessive mortality was observed at lower temperature thresholds (lower than the MMT of $20^{\circ} \mathrm{C}$ ) during May, although other confounding factors may have played a role during this period, when the country had just finished its first lockdown. This heatmortality link was also observed for temperatures as those registered during summer, which although persistent, were on the overall fairly moderate temperature anomalies, when compared to other recent HW events. In other words, exposure to HW conditions has killed more people during 2020 than in previous years (probably around a 50\% factor or higher), and not all deaths were intrinsically related with the direct impacts of warm weather. This was particularly notable during the onset of the HWs in late May and late June, when daily mortality rates abruptly entered the upper tertile, in agreement with previous results showing that large Iberian cities are particularly prone to significant increments in mortality during the first HWs, typically in late May and June (García-Herrera et al. 2005). Moreover, these authors noted that mortality rates in Iberian countries tend to drop as consecutive HWs occur, contrarily to sharp rises observed during their onset, probably as a combination of (i) decrease in fragile individuals who decease in the initial stages of HWs and (ii) an "acclimatization" to above-average conditions by the overall population as the season progresses. However, our results show that during this unique summer of 2020, this damping temporal factor was much less evident due to the amplification factor explained before.

Heat-related deaths are usually associated with comorbidities such as cardiovascular disease, ischemic heart disease, diabetes, and related to hospital admissions due to dehydration, heat stroke, heat exhaustion, and respiratory problems (Åström et al. 2011; Kunst et al. 1993; Semenza et al. 1999) and to a relatively shorter lag time between the trigger of symptoms and death when compared to cold spells (Curriero et al. 2002; Mackenbach et al. 1993). Therefore, a swift access to medical care is crucial to reduce fatality rates, which are particularly exacerbated during HWs. Furthermore, and due to SARS-CoV-2 effects on cardiovascular, respiratory, and renal systems (CDC 2020; Soleimani 2020; Zhang et al. 2020), risk of death by referred causes might be increased after COVID-19 infection, thus further amplifying mortality rates from acute disease during hot spells. Unfortunately, the drastic reduction in ER admission for urgent cases, together with disruptions in healthcare 
efficiency observed since the beginning of the pandemic, might have critically hampered rates of life-saving success for these heat-related illnesses. This outcome stresses the need to more efficiently provide awareness to the general population about HW-related complications (Martinez et al. 2020), risks of mortality, and access to healthcare, especially under such atypical conditions as the ones experienced since 2020 (Bose-O'Reilly et al. 2021; Rhubart 2020), under the constraints of being amidst a pandemic (IFRC 2020). Furthermore, such awareness and mitigation measures become even more strident in the context of recurrent and increasingly frequent HW episodes in western Europe (Sousa et al. 2020), associated to a warming climate (Guo et al. 2018; USAID 2019; WHO 2009), and on the significant impacts on the capacity of healthcare in a population with increasing average age distribution, as in Portugal (INE 2020).

To finalize, we must acknowledge that demographic changes (aging population, at both national and regional scales) along the study period might contribute with a strong non-linear component. We believe this factor has been minimized by adjusting expected mortality based on observed trends during 2009-2019. However, a note of caution on this effect must be considered. Other behavioral changes were observed during the pandemic, particularly in terms of mobility, which was significantly reduced since March 2020, and only returning to values similar to the pre-pandemic during 2021. These changes were influenced by the large share of people working remotely, the reduction in public transportation use, and generalized business closure, amongst others, and should also be considered as non-linear components shaping the effects of mortality series during 2020. Also, it is crucial to note that at the time this study is performed, specific causes for each individual death registered during 2020 are not yet available. This in-depth analysis should be relevant for the verification of the actual ratio of deaths during 2020 that can be attributable to acute diseases, matching them to exposure to hot weather or other confounding factors, besides COVID-19. This might also influence notification of causes of death, including distinction between "with COVID-19" and "from COVID-19." Also, the temperature-mortality model presented here should be interpreted with precaution, as any statistical modeling approach. Nevertheless, we believe the results presented in this work provide strong evidence on the crucial combined roles of HWs and indirect COVID-19 causes to the dramatic mortality burden observed during summer 2020 in Portugal.

Supplementary Information The online version contains supplementary material available at https://doi.org/10.1007/s00484-021-02192-z.

Acknowledgements JLG acknowledges FCT (Fundação para a Ciência e a Tecnologia) for the PhD Grant 2020.05198.
Author contribution PMS, RMT, and AMR were responsible for the initial study concept and design. PMS, JLG, AR, AR, SS, and AT were responsible for acquisition of data. PMS was responsible for the calculations, figures, and initial draft of the manuscript. PMS, RMT, AMR, JLG, AR, SS, and AT were responsible for the discussion, revision, and preparation of the manuscript until its final version.

Funding This work was partially funded by national funds through Fundação para a Ciência e a Tecnologia (FCT) under project IMPECAF (PTDC CTA-CLI28902 2017) and project HOLMODRIVE (PTDC/CTA-GEO/29029/2017). AR, PMS, and RT are also grateful by the FCT funding UID GEO 50019 2020-Instituto Dom Luiz.

\section{References}

Analitis A, Katsouyanni K, Biggeri A, Baccini M, Forsberg B, Bisanti L, Kirchmayer U, Ballester F, Cadum E, Goodman PG, Hojs A, Sunyer J, Tiittanen P, Michelozzi P (2008) Effects of cold weather on mortality: results from 15 European cities within the PHEWE project. Am J Epidemiol 168(12):1397-1408. https://doi.org/10. 1093/aje/kwn266

Antunes L, Silva SP, Marques J et al (2017) The effect of extreme cold temperatures on the risk of death in the two major Portuguese cities. Int J Biometeorol 61:127-135. https://doi.org/10.1007/ s00484-016-1196-x

Åström DO, Forsberg B, Rocklöv J (2011) Heat wave impact on morbidity and mortality in the elderly population: a review of recent studies. Maturitas 69(2011):99-105. https://doi.org/10.1016/j. maturitas.2011.03.008

Benmarhnia T, Deguen S, Kaufman JS, Smargiassi A (2015) Review article: vulnerability to heat-related mortality: a systematic review, meta-analysis, and meta-regression analysis. Epidemiology 26(6):781-793

Borg M, Bi P, Nitschke M, Williams S, McDonald S (2017) The impact of daily temperature on renal disease incidence: an ecological study. Environ Health 16(1):114

Bose-O'Reilly S, Daanen H, Deering K, Gerret N, Huynen MMTE, Lee J, Karrasch S, Matthies-Wiesler F, Mertes H, Schoierer J, Shumake-Guillmot J, van den Hazel P, van Loenhout JAF, Nowak D (2021) COVID-19 and heat waves: new challenges for healthcare systems. Environ Res 198:111153. https://doi.org/10.1016/j. envres.2021.111153

Calado R, Nogueira PJ, Catarino J, Paixão EJ, Botelho J, Carreira M, Falcão JM (2004) A onda de calor de Agosto de 2003 e os seus efeitos sobre a mortalidade da população portuguesa. Revista Portuguesa de Saúde Pública 22:14

CDC, Centers for Disease Control and Prevention (2020) COVID-19: long-term effects. Accessible at: https://www.cdc.gov/coronavirus/2019-ncov/long-term-effects.html. Accessed 16 Sept 2021

Cheng J, Xu Z, Bambrick H, Prescott V, Wang N, Zhang Y, Su H, Tong S, Hu W (2019) Cardiorespiratory effects of heatwaves: a systematic review and meta-analysis of global epidemiological evidence. Environ Res 177:108610. https://doi.org/10.1016/j. envres.2019.108610

Curriero FC, Heiner KS, Samet JM, Zeger SL, Strug L, Patz JA (2002) Temperature and mortality in 11 cities of the eastern United States. Am J Epidemiol 155:80-87. https://doi.org/10.1093/aje/ 155.1.80

ECDC, European Centre for Disease Prevention and Control (2019) https://www.ecdc.europa.eu/en/publications-data/regionalsituation-assessment-seasonal-influenza-2019-2020. Accessed 18 Dec 2019 
Forzieri G, Cescatti A, E Silva FB, Feyen L (2017) Increasing risk over time of weather-related hazards to the European population: a data-driven prognostic study. Lancet Planet Health 1(5):e200-e208

Fouillet A, Rey G, Laurent F, Pavillon G, Bellec S, GhihenneucJouyaux C, Clavel J, Jougla E, Hémon D (2007) Excess mortality related to the August 2003 heat wave in France. Int Arch Occup Environ Health 80(1):16-24. https://doi.org/10.1007/ s00420-006-0089-4

Freitas AR, Donalisio MR (2018) Excess of mortality in adults and elderly and circulation of subtypes of influenza virus in Southern Brazil. Front Immunol. 8:1903

Garcia AC, Nogueira PJ, Falcão JM (1999) Onda de calor de Junho de 1981 em Portugal : efeitos na mortalidade. Revista Portuguesa de Saúde Pública 1999. Volume temático, № 1 (1999), p. 67-77

García-Herrera R, Díaz J, Trigo RM, Hernandez E (2005) Extreme summer temperatures in Iberia: health impacts and associated synoptic conditions. Ann Geophys 23:239-251

García-Herrera R, Días J, Trigo RM, Luterbacher J, Fischer EM (2010) A review of the European summer heat wave of 2003. Crit Rev Environ Sci Technol 40:267-306. https://doi.org/10.1080/10643 380802238137

Gasparrini A, Armstrong B (2011) The impact of heat waves on mortality. Epidemiology 22(1):68-73

Gasparrini A, Guo Y, Hashizume M, Lavigne E, Zanobett A, Schwartz J, Tobias A, Tong S, Rocklöv J, Forsberg B, Leone M, De Sario M, Bell ML, Guo Y-LL, Wu C-F, Kan H, Yi S-M, De Sousa Zanotti Stagliorio Coelho M, Saldiva PHN, Honda Y, Kim H, Armstrong B (2015) Mortality risk attributable to high and low ambient temperature: a multicountry observational study. Lancet 386(9991):369-375. https://doi.org/10.1016/S0140-6736(14) 62114-0

Geirinhas JL, Russo A, Libonati R, Trigo RM, Castro LCO, Peres LF, Magalhães MAFM, Nunes B (2020) Heat-related mortality at the beginning of the twenty-first century in Rio de Janeiro, Brazil. Int J Biometeorol 64:1319-1332

Guo et al (2018) Heat wave and mortality: a multicountry, multicommunity study. Environ Health Perspect 125(8)

Hersbach H, Bell B, Berrisford P, Hirahara S, Horányi A, MuñozSabater J, Nicolas J, Peubey C, Radu R, Schepers D, Simmons A, Soci C, Abdalla S, Abellan X, Balsamo G, Bechtold P, Biavati G, Bidlot J0, Bonavita M, De Chiara G, Dahlgren P, Dee D, Diamantakis M, Dragani R, Flemming J, Forbes R, Fuentes M, Geer A, Haimberger L, Healy S, Hogan RJ, Hólm E, Janisková M, Keeley S, Laloyaux P, Lopez P, Lupu C, Radnoti G, de Rosnay P, Rozum I, Vamborg F, Villaume S, Thépaut JN (2020) The ERA5 global reanalysis. Q J R Meteorol Soc: 1-51, https://doi.org/10. 1002/qj.3803

IFRC, International Federation of Red Cross and Red Crescent Societies (2020) Heat and COVID-19 information series. Extreme Heat during the COVID-19 Pandemic. http://climatecentre.org/downl oads/files/HWG\%20appendix\%20Extreme\%20Heat\%20during\% 20the\%20COVID-19\%20pandemic.pdf

INE, Instituto Nacional de Estatística (2020) Informação à comunicação social: projeções de população residente. Accessible at: https://www.ine.pt/xportal/xmain?xpid=INE\&xpgid=ine destaques\&DESTAQUESdest_boui=406534255\&DESTA QUESmodo=2\&xlang=pt. Accessed 31 Mar 2020

INE, Instituto Nacional de Estatística (2021) Base de dados de mortalidade, Portugal. Accessible at: https://www.ine.pt/xportal/ xmain? $x$ pid $=I N E \& x p g i d=$ ine_indicadores\&contecto=pi\&indOc orrCod=0008235\&selTab=tab0. Accessed 27 Apr 2021

INS, Instituto Nacional de Saúde (2021) Influenza epidemiological surveillance bulletin. [Accessed 2021 Feb 09]. Accessible at: http:// www.insa.min-saude.pt/category/informacao-e-cultura-cientifica/ publicacoes/atividade-gripal/
IPMA, Instituto Português do Mar e da Atmosfera (2020): Relatório Julho 2020. Accessible at: https://www.ipma.pt/resources.www/ docs/im.publicacoes/edicoes.online/20200819/WclaOXLKEY FUYNvOBvDq/met_20200701_20200731_fog_mm_co_pt.pdf. Accessed Aug 2020

Kang et al (2016) Heat, heat waves, and out-of-hospital cardiac arrest. Int J Cardiol 221:232-237

Kenny GP, Yardley J, Brown C, Sigal RJ, Jay O (2010) Heat stress in older individuals and patients with common chronic diseases. CMAJ 182(10):1053-1060

Kunst AE, Looman CWN, Mackenbach JP (1993) Outdoor air temperature and mortality in the Netherlands: a time-series analysis. Am J Epidemiol 137:331-341

Lee WS, Kim WS, Lim YH, Hong YC (2018) High temperatures and kidney disease morbidity: a systematic review and meta-analysis. J Prev Med Public Health 52(1):1-13. https://doi.org/10.3961/ jpmph.18.149

Lian T, Fu Y, Sun M, Yin M, Zhan Y, Huang L, Huang J, Xu Z, Mao C, Ni J, Liu G (2020) Effect of temperature on accidental human mortality: a time-series analysis in Shenzhen, Guangdong Province in China. Nat Sci Rep 10:8410

Mackenbach JP, Looman CW, Kunst AE (1993) Air pollution, lagged effects of temperature, and mortality: the Netherlands 1979-87. J Epidemiol Community Health 47(2):121-126. https://doi.org/ 10.1136/jech.47.2.121

Mafham MM, Spata E, Goldacre R, Gair D, Curnow P, Bray M, Hollings S, Roebuck C, Gale CP, Mamas MA, Deanfield JE, de Belder MA, Luescher TF, Denwod T, Landray MJ, Emberson JR, Collins R, Morris EJA, Casadeit B (2020) Baigen C (2020): COVID-19 pandemic and admission rates for and management of acute coronary syndromes in England. Lancet 396:381-89. https://doi.org/ 10.1016/S0140-6736(20)31356-8

Marijon E, Karam N, Jost D, Perrot D, Frattini B, Derkenne C, Sharifzadehgan A, Waldmann V, Beganton F, Narayana K, Lafont A, Bougouin W, Jouven X (2020) Out-of-hospital cardiac arrest during the COVID-19 pandemic in Paris, France: a population-based, observational study. The Lancet Public Health 5(8):E437-E433. https://doi.org/10.1016/S2468-2667(20) 30117-1

Martinez GS, Linares C, de'Donato F, Diaz J, (2020) Protect the vulnerable from extreme heat during the COVID-19 pandemic. Environ Res 187:109684. https://doi.org/10.1016/j.envres.2020. 109684

Mesnier J, Cottin Y, Coste PC, Ferrari E, Schiele F, Lemesle G et al (2020) Hospital admissions for acute myocardial infarction before and after lockdown according to regional prevalence of COVID-19 and patient profile in France: a registry study. The Lancet Public Healt 5(10):E536-E542

Mitchell D, Heaviside C, Vardoulakis S, Huntingford C, Masato G, Guillod BP, Frumhoff A, Wallom D, Allen M (2016) Attributing human mortality during extreme heat waves to anthropogenic climate change. Environ Res Lett 11:074006. https://doi.org/10. 1088/1748-9326/11/7/074006

Nairn J, Fawcett R, Ray D (2009) Defining and predicting excessive heat events, a national system. Understanding high impact weather. CAWCR technical report 017. Bureau of Meteorology, Melbourne, pp 83-86

Nogueira PJ, Nobre MA, Nicola PJ, Furtado C, Carneiro AV (2020a) Excess mortality estimation during the COVID-19 pandemic: preliminary data from Portugal. Acta Med Port. https://doi.org/ 10.20344/amp.1392

Nogueira PJ, Nobre MA, Nicola PJ, Costa A, Ribeiro RM, Furtado C, Nicolau LB, Camarinha C, Luís M, Abrantes R, Carneiro AV (2020b) The role of health preconditions on COVID-19 deaths in portugal: evidence from surveillance data of the first 20293 infection cases. J Clin Med 
Nunes B, Paixão E, Dias CM, Nogueira P, Falcão JM (2011) Air conditioning and intrahospital mortality during the 2003 heatwave in Portugal: evidence of a protective effect. Occup Environ Med 68(3):218-223. https://doi.org/10.1136/oem.2010.058396

Onozuka D, Hagihara A (2017) Out-of-hospital cardiac arrest risk attributable to temperature in Japan. Sci Rep 7:39538. https:// doi.org/10.1038/srep39538

Péres WE, Ribeiro AFS, Russo A, Nunes B (2020) The association between air temperature and mortality in two Brazilian health regions. Climate 8:16. https://doi.org/10.3390/cli8010016

Phung D, Chu C, Rutherford S, Nguyen HLT, Do CM, Huang C (2017) Heatwave and risk of hospitalization: a multi-province study in Vietnam. Environ Pollut 220(Pt A):597-607. https://doi.org/10. 1016/j.envpol.2016.10.008

Rhubart D (2020) Preventing heat-related fatalities during the COVID-19 pandemic. Lerner Center for Public Health Promotion: Research Brief \#24. https://lernercenter.syr.edu/wp-content/ uploads/2020/06/Rhubart.pdf. Accessed 1 Jul 2020

Robine JM, Cheung SLK, Le Roy S, Van Oyen H, Griffiths C, Michel JP, Herrmann FR (2008) Death toll exceeded 70,000 in Europe during the summer of 2003. Comptes Dendus Biologies 331(2):171-178. https://doi.org/10.1016/j.crvi.2007.12.001

Rocklöv J, Forsberg B, Ebi K, Bellander T (2014) Susceptibility to mortality related to temperature and heat and cold wave duration in the population of Stockholm County. Sweden Glob Health Action 7:22737

Royé D, Codesito R, Tobías A, Taracido M (2020) Heat wave intensity and daily mortality in four of the largest cities of Spain. Environ Res 182:109027. https://doi.org/10.1016/j.envres.2019.109027

Sherbakov T, Malig B, Guirguis K, Gershunov A, Basu R (2018) Ambient temperature and added heat wave effects on hospitalizations in California from 1999 to 2009. Environ Res 160:83-90. https://doi.org/10.1016/j.envres.2017.08.052

Sheridan SC, Lee CC, Smith ET (2020) A comparison between station observations and reanalysis data in the identification of extreme temperature events. Geophys Res Lett 47: e2020GL088120. https://doi.org/10.1029/2020GL088120

Semenza JC, McCullough JE, Flanders WD, McGeehin MA, Lumpkin JR (1999) Excess hospital admissions during the July 1995 heat wave in Chicago. Am J Prev Med 16:269-277

SICO-eVM (2021) e-Mortality surveillance. DGS (Direção Geral da Saúde). Accessible at: https://evm.min-saude.pt/

Silva SPD, Roquette R, Nunes B, Dias CM (2016) A onda de calor de junho e julho de 2013: análise dos seus impactes na mortalidade por distrito de Portugal Continental. Boletim Epidemiológico Observações 5:27-29
SNS, Serviço Nacional de Saúde (2021) Monitorização diária dos serviços de urgência. Accessible at: https://www.sns.gov.pt/monit orizacao-do-sns/servicos-de-urgencia/caracterizacao-urgencias/

Soleimani M (2020) Acute kidney injury in SARS-CoV-2 infection: direct effect of virus on kidney proximal tubule cells. Int J Mol Sci 21(9):3275

Sousa PM, Barriopedro D, García-Herrera R, Ordóñez C, Soares PMM, Trigo RM (2020) Distinct influences of large-scale circulation and regional feedbacks in two exceptional 2019 European heatwaves. Commun Earth Environ 1:48. https://doi.org/10.1175/ JCLI-D-19-0348.1

Torres AR, Silva S, Nunes B, Rodrigues AP (2020) Excesso de mortalidade em Portugal associado ao período de calor extremo em agosto de 2018: um instrumento ao serviço da intervenção em saúde pública. Bol Epidemiológico Obs 9(26):9-13

Torres AR, Silva S, Nunes B, Dias C, Rodrigues AP (2021) Monitorização da mortalidade 2020. Instituto Nacional de Saúde Doutor Ricardo Jorge. http://hdl.handle.net/10400.18/7219

Tran D, Vaudry W, Moore D, Bettinger JA, Halperin SA, Scheifele DW et al (2016) Hospitalization for influenza A versus B. Pediatrics 138(3):e20154643. https://doi.org/10.1542/peds.2015-4643

Trigo RM, Ramos AM, Nogueira P (2009) Evaluating the impact of extreme temperature based indices in the 2003 heatwave excessive mortality in Portugal. Environ Sci Policy 12(7):844-854

USAID, United States Agency for International Development (2019) Heat waves and human health-emerging evidence and experience to inform risk management in a warming world. Accessible at: https://www.climatelinks.org/sites/default/files/asset/docum ent/2019_USAID-ATLAS_Heat-Waves-and-Human-Health.pdf. Accessed Feb 2019

Uy-Evanado A, Chugh HS, Sargsyan A, Nakamura K, Mariani R, Hadduck K, Salvucci A, Jui J, Chugh SS, Reinier K (2021) Out-ofhospital cardiac arrest response and outcomes during the COVID19 pandemic. JACC Clin Electrophysiol 7(1):6-11. https://doi.org/ 10.1016/j.jacep.2020.08.010

WHO, World Health Organization (2009) Improving public health responses to extreme weather/heat-waves - EuroHEAT. Accessiblea at: https://www.euro.who.int/_data/assets/pdf_file/0010/ 95914/E92474.pdf?ua=1

WHO (2018) COP24 special report: health and climate change. World Health Organization, Geneva. CIP data are available at ilable at http://apps.who.int/iris. Accessed 2018-12-04

Zhang Y, Geng X, Tan Y, Li Q, Xu C, Xu J, Wang H, (2020) Newunderstanding of the damage of SARS-CoV-2 infection outside the respiratory system. Biomed Pharmacother127:110195. https://doi. org/10.1016/j.biopha.2020.110195 